\title{
LONG AND SHORT-RUN LINKAGES IN CEE STOCK MARKETS: IMPLICATIONS FOR PORTFOLIO DIVERSIFICATION AND STOCK MARKET INTEGRATION
}

by

\author{
MANOLIS N. SYLLIGNAKIS ${ }^{1 *}$ AND GEORgIOS P. KOURETAS ${ }^{2}$
}

July 2006

\begin{abstract}
This paper examines the short- and long-term relationships between seven Central Eastern European (CEE) stock markets and two developed stock markets, namely the German market and the US market. Application of the Gonzalo and Granger (1995) methodology indicates that the examined stock markets are partially integrated, while there is also evidence that the five stock markets in the central Europe (Czech Republic, Hungary, Poland, Slovenia and Slovakia) together with the German and the US stock markets have a significant common permanent component, which drives this system of stock exchanges in the long run. Contrary, the Estonian and Romania markets are segmented. A DCC model indicates that the short - term interdependencies between the CEE stock markets and the developed stock markets have strengthened during the Asian and Russian crises but since then (except for the Czech Republic, Hungary, Poland) they returned almost to their initial (relatively low) levels. Moreover, significantly increased volatility is observed during the Russian crisis period for all the markets under enquiry.
\end{abstract}

Keywords: Central Eastern European equity markets, Market Integration, Common trends, DCC, SWARCH-L.

JEL classification: G15, C12, C32, F36

\footnotetext{
* The authors acknowledge generous financial support from PENED 2003 (research grant (03ED46) financed by the General Secretariat for Research and Technology of the Ministry of Development). We thank Dr. Minoas Koukouritakis for providing us his Matlab code for the common trend eigenvalue problem. An earlier version of this paper was presented at the Workshop on Financial Market Development in the Central and Eastern European Countries, CERGE-EA, Prague, 26-27 May 2006 and thanks are due to workshop particamts and many helpful comments and discussions. The usual caveat applies.

${ }^{1}$ Department of Business Administration, Athens University of Economics and Business, 76 Patission Street, GR-10434, Athens, Greece, tel. 00302108203867, email: msyllign@aueb.gr.

${ }^{2}$ Department of Economics, Univeristy of Crete, University Campus, GR-74100, Rethymno, Greece, tel. 00302831077412, fax: 00302831077406, email: kouretas@econ.soc.uoc.gr. (corresponding author).
} 


\section{Introduction}

In recent years, global markets have tended to become more integrated as a result of a broad trend toward liberalization and deregulation in the money and capital markets of developed as well as developing countries. Finance specialists have given considerable attention to the relationships between national stock markets, in order to explore potential benefits from international diversification, mostly in the emerging markets of Asia and Latin America. Given the currency crises and the political instability of those markets in recent years, investors are now actively looking for other emerging markets, such as those in Central Eastern Europe.

After the collapse of communist and socialist regimes at the beginning of 1990s, a number of Central and Easter European (CEE) economies established capital markets as part of their transition process towards adopting the mechanisms of a market economy. As a result, a number of stock markets have been established in the region. Since then they displayed considerable growth in size and degree of sophistication. Moreover, in order to attract foreign capitals, they have tried to adapt their standards to international ones, by improving disclosure practices of firms, order execution, ownership rights, and by bringing down limitations to international capital flows. The entrance in the European Union of these countries on May 1, 2004, as well as the agreed accession of Romania and Bulgaria on 2007, gave a big boost on these markets and attracted the interest of many investors worldwide, who previously refrained to invest in legally open markets because of real or perceived political, liquidity and corporate governance risks.

The case of integration among the stock markets has focused the interest of many researchers, something that is revealed by the large literature on the different aspects of 
stock market integration. Evidence of integration among the stock markets is important, particularly for the long-term investors, since that means that the national stock markets share a single common trend, and there are few transitory excursions from this trend, implying reduced long-term gains from international diversification.

The current literature is supportive of the fact that the major international stock markets are converging at least over the long-term. Kasa (1992) using monthly and quarterly data on the markets of US, UK, Canada, Germany and Japan for the period between 1974 and 1990, and utilizing the Johansen (1988) multivariate cointegration technique, proposes that a single common stochastic component binds national equity markets together. Moreover, according to Fraser and Oyefeso (2005) the US, UK and seven European equity markets are linked by a common stochastic trend and therefore are perfectly correlated in the long-term, while any short-run diversification gains tend to be short-lived. Additionally, Georgoutsos and Kouretas (2001) conducted cointegration analysis using monthly data for the US, the UK, Germany and Japan for the period 19802000. They showed that cointegration was established among the examined markets during the early 1990s which provides support to the argument that the stock markets have become more integrated since a smaller number of stochastic trends drive the system.

In the light of growing interdependencies among world stock markets, numerous studies investigated the extent to which emerging stock markets are integrated with the global markets (see for example: Garret and Spyrou (1996), De Fusco et al. (1996), Bekaert and Harvey (1995), Bekaert and Harvey (1997) and Phylaktis and Ravazzolo (2002)). Little attention has been directed towards the question of the extent to which 
emerging European stock markets are integrated with global markets and the extent to which are affected by global shocks. Among the CEE markets, those of the Vysegrad countries (Poland, Hungary and the Czech Republic) have attracted most of the attention of the researchers, while the markets of their regional counterparts (Slovakia, Slovenia, Romania, Bulgaria and the Baltic countries) have not been subject of research to date.

It is evident that the CEE stock markets are attracting more and more interest and they play a far more important role in the international financial environment. Moreover, since the contribution of these markets to internationally diversified portfolios has grown substantially, it is crucial to understand the relationship between these markets and the developed markets. The purpose of this paper is to explore the short- and long term relationships between seven Central Eastern European stock markets and two developed stock markets, namely the German market and the US market. Contrary to all the other papers that have been done in the past we include in our sample almost ${ }^{1}$ all the markets in the area that entered already in the EU and a forthcoming member of EU Romania. A further contribution of this study is that the case of integration among the markets in our sample is examined using a variety of econometric methodologies, in order to achieve robustness of the results.

First, we applied the Johansen (1988) multivariate cointegration methodology to study for the number of cointegration relations among the examined group of markets, while we utilize the Gonzalo and Granger (1995) methodology to identify, estimate and test for the number of common trends among the group of the examined stock markets. Second, we use the Dynamic Conditional Correlation (DCC) specification recently

\footnotetext{
${ }^{1}$ Bulgaria, Latvia and Lithuania are not included in this study due to data inadequacy. Nevertheless, our sample is representative of the three different market regions, namely the Central Eastern Europe (Czech Republic, Hungary, Poland, Slovakia, Slovenia), the Baltic (Estonia) and the Balkans (Romania).
} 
proposed by Engle (2002) and Engle and Sheppard (2001), in order to estimate the conditional relationships between the examined stock markets in the CEE region and the two developed stock markets. Finally, in accordance with Rigobon and Forbes (2002) who argue that the increased correlations over crises periods are due to an increase in volatility in world markets because of the crisis, we apply the Markov Switching ARCHL (SWARCH-L) model of Hamilton and Susmel (1994) to study for structural breaks in volatility of the examined markets during the examined period.

Our results, based on daily and weekly data from January 1, 1995 to December 25,2005 , indicate that the examined stock markets are partially integrated, since they have more common trends than cointegrating relations that bind them together in the long run. There is also evidence that the five stock markets in Central Europe (Czech Republic, Hungary, Poland, Slovenia and Slovakia) together with the German and the US stock markets have a significant common permanent component ${ }^{2}$, which drives this system of stock exchanges in the long run, while the Estonian and the Romanian markets are segmented. The DCC analysis suggests that short - term interdependencies between the CEE stock markets and the developed stock markets are affected mostly by crises in other emerging market regions (i.e. Asian and Russian crises). Moreover, the conditional correlations between the bigger CEE markets, in terms of market capitalization (Czech Republic, Hungary, Poland) and the developed markets have increased during the examined period, confirming the increased integration, while the conditional correlations between the rest of the markets in the region and the developed markets had raised significantly through the period of the two crises but since then they returned almost to

\footnotetext{
${ }^{2}$ Is the group of markets which dominate the common trends in the cointegrating system and drive the other markets in the region.
} 
their initial (low) levels. Finally, the application of the SWARCH-L model indicates a significantly increased level of volatility through the period of the Russian crisis, a finding that is consistent with Rigobon and Forbes (2002) who argue that the increased correlations over crises periods are due to an increase in volatility in world markets because of the crisis.

The remainder of the paper is organized as follows. The next section presents and discusses a review of the literature. Section 3 presents basic information about the seven examined Central Eastern European markets. In Section 4 the methodology used in this study is presented, while section 5 discusses the data and the preliminary empirical results. Section 6 reports the empirical results and section 7 provides our summary and concluding remarks.

\section{Review of the literature}

The study of Linne (1998) is most likely the first one that focuses on the investigation of the long-run linkages among the Eastern European markets (Poland, Hungary, Czech Republic, Slovak Republic and Russia) and a group of developed markets (Germany, UK, France, Italy, Switzerland, US and Japan). Weekly data were used for the market indices expressed in US dollars, over the period from 1991 to 1997. The author concluded that among the CEE markets only Slovakian stock market showed cointegration relations with all developed stock markets, while the majority of the CEE stock markets are driven by domestic factors.

In another study Gelos and Sahay (2000) investigate the impact of various external crises on CEE stock markets. They found increasing financial market correlation 
since 1993, particularly around the Russian crisis. The Hungarian market appeared to be mostly affected by that crisis. This finding is consistent with Schotman and Zalewska (2005) who documented that the Hungarian market being most and the Czech market being least sensitive to the Asian and Russian crises, something that explained by the fact that among the three emerging markets discussed in that study the Hungarian market had the highest foreign share ownership level and the Czech market the lowest.

Gilmore and McManus (2001) examined the short and long-term relationships between the US stock market and three Central European markets (Hungary, Poland, Czech Republic), over the 1995-2001 period . Low short-term correlations between the CEE markets and the US are found, while the application of the Johansen cointegration procedure indicates that there is no long-term relationship. The last finding is consistent with Egert and Kocenda (2005) who found no robust cointegration relationship between the three Vysegrad markets and a group of developed markets, using intraday data. Rockinger and Urga (2001) explored integration of the four emerging markets (Czech Republic, Hungary, Poland, Russia) over the 1994-1997 period using an extended Bekaert and Harvey (1997) model. They found that German market influence significantly both Czech and Hungarian stock returns, while Czech and Polish stock returns seem not to be influenced by the US. Scheicher (2001) study the regional and global integration of stock markets in Hungary, Poland and the Czech Republic, estimating a vector autoregression with a multivariate GARCH component. Daily data were used for the 1995-1997 period and the main empirical results indicate that, to some extent, the stock markets of Eastern Europe's leading economies are influenced by 
Western financial markets. Moreover, regional integration among the three countries is documented, in particular between Hungary and Poland.

\section{Market characteristics}

Following the fall of communism in Central Eastern Europe, a number of stock exchanges, which had been closed in the postwar era reopened. The first stock exchange that reopened in the area was the Budapest Stock Exchange (BSE), on June 21, 1990, followed by the Warsaw Stock Exchange (WSE) on April 16, 1991. Since then the CEE countries have taken steps towards liberalization of their financial markets. They open their economies to those of the industrial world, increase trade and capital flows and reform the financial institutions to function in a competitive environment.

The main information about the examined CEE stock markets is presented in Table 1. The larger stock markets in the CEE region, in terms of market capitalization, are the Poland, the Czech, the Hungarian and the Slovenian, with market capitalization of $97.56,35.82,24.57$ and 15.12 billion dollars respectively. The smallest market is the Slovakian market with market capitalization of only 4.10 billion dollars. The exchanges also reflect the different privatization strategies pursued by the CEE countries. The number of firms in the Czech and Slovakian stock exchanges was initially large, following the first of several mass waves of privatization, which led to a large number of firms being listed on the stock exchange. Since then, the majority of those firms have been delisted. Contrary, on the rest of the exchanges the number of listed firms has grown slowly, as a result of a gradual approach to privatization. 


\section{Methodology}

\subsection{Cointegration and common trends models}

The case of integration among seven Central Eastern European stock markets and two developed stock markets, namely the German and the US markets is examined in this study using the methodology of cointegration analysis. The statistical notion of cointegration is well suited to study the co-movements of a set of variables in the long run. A set of nonstationary variables is said to be cointegrated if there exist linear combinations (cointegrating relations) among them that are stationary. The existence of $r$ cointegrating relations in a set of $n$ variables means that there must also exist $n-r$ common stochastic trends that are nonstationary and move these variables around their equilibrium paths. The most of the studies to date have been concerned with estimating and analyzing cointegrating relations among the examined stock markets. Common trend analysis can be equally useful and insightful. In the present paper we use the Gonzalo and Granger (1995) methodology to identify, estimate and test for the number of common trends among the group of the examined stock markets.

We utilize the Johansen (1988) multivariate cointegration tests to ask how many common stochastic trends, or equivalently, how many cointegrating vectors, there are in the stock markets in our sample. The maximum likelihood theory of cointegration assumes that the stochastic variables are integrated of order one (I(1)), and that the data generating process is a Gaussian vector autoregressive model of finite order k, VAR(k). Assume the $n$-dimensional column vector $X_{t}$ has an autoregressive representation with Gaussian errors $\varepsilon_{t}$.

$$
X_{t}=\mu+A_{1} X_{t-1}+\cdots+A_{k} X_{t-k}+\varepsilon_{t}
$$


Then the VAR(k) can be written in a vector error-correction model (VECM) form

as

$$
\Delta \mathrm{X}_{t}=\sum_{i=1}^{k-1} \Gamma_{i} \Delta \mathrm{X}_{t-i}+\Pi \mathrm{X}_{t-1}+\mu+\varepsilon_{t}
$$

Where $\Pi$ and $\Gamma_{i}$ are $\mathrm{n} \times \mathrm{n}$ matrices of coefficients, $\mu$ is the deterministic term and $\varepsilon_{t}$ is a $\mathrm{n} \times 1$ multivariate normal random error with mean zero and variance matrix $\Omega$ that is independent across time periods. The rank of $\Pi$ matrix determines the number of distinct cointegrating vectors that exist between the variables in $\mathrm{X}$. $\Pi$ therefore represents the long-run impact matrix. If $\Pi$ has rank, $r$, then there are $r$ cointegrating relationships between $\mathrm{X}_{t}$, or, $\mathrm{n}$-r common stochastic trends, where $\mathrm{n}$ is the number of stock indices in our sample.

The number of cointegrating vectors reveals the extent of integration across stock markets. If $\mathrm{n}-\mathrm{r}=0$ (full rank), there is no stochastic trend, all the elements in $X_{t}$ are stationary $(\mathrm{I}(0))$ and cointegration is not defined. If $\mathrm{n}-\mathrm{r}=\mathrm{n}(\mathrm{r}=0)$, there are no stationary long-run relationships among the elements of $X_{t}$. In the intermediate case, when $0<\mathrm{r}<\mathrm{n}$ there are $\mathrm{r}$ stationary linear compinations of the elements of $\mathrm{X}_{t}$ and $\mathrm{n}-\mathrm{r}$ non stationary common trends. There will exist $\mathrm{n} \times \mathrm{r}$ matrices, $\alpha$ and $\beta$, such that:

$$
\Pi=\alpha \beta^{\prime}
$$

where $\alpha$ is the adjustment matrix and the columns of $\beta$ are the $r$ linearly independent cointegrating vectors. The reduced rank of matrix $\Pi$ would imply that while long-run integration is not complete, the convergence process is underway with the number of 
independent stochastic trends reflecting the extent of this convergence. If however, $n-r$ $=1$, there is a single stochastic trend and hence a single permanent force that creates the non-stationary property of the data.

Because of the normality assumption, the reduced rank of the $\Pi$ matrix can be tested using the maximum likelihood approach. From the regression of $\Delta X_{t}$ and $X_{t-1}$ on $\Delta X_{t-1}, \ldots, \Delta X_{t-k+1}$ and $\mu$ are given the residuals $R_{0 t}$ and $R_{1 t}$, respectively, and residual product matrices

$$
S_{i j}=T^{-1} \sum_{t=1}^{T} R_{i t} R_{j t}^{\prime}, i, j=0,1
$$

Solving the eigenvalue problem

$$
\left|\lambda S_{11}-S_{10} S_{00}^{-1} S_{01}\right|=0
$$

for eigenvalues $1>\hat{\lambda}_{1}>\cdots>\hat{\lambda}_{n}>0$ and eigenvectors $\hat{V}=\left(\hat{v}_{1}, \ldots, \hat{V}_{n}\right)$, normalized such that $\hat{V}^{\prime} S_{11} \hat{V}=I$, we get the maximum likelihood estimators (MLE) of $\alpha$ and $\beta$ as $\hat{\alpha}=S_{01} \hat{\beta}$ and $\hat{\beta}=\left(\hat{v}_{1} \ldots \hat{v}_{n}\right)$, where $\left(\hat{v}_{1} \ldots \hat{v}_{n}\right)$ are the eigenvectors associated with the $\mathrm{r}$ largest eigenvalues of equation (5).

In order to test the null hypothesis that $\operatorname{rank}(\Pi) \leq r$ against the alternative hypothesis that $\operatorname{rank}(\Pi)=n$, we use the Trace statistic by Johansen and Juselius (1990), which is given by

$$
\text { Trace }=-T \sum_{i=r+1}^{n} \ln \left(1-\hat{\lambda}_{i}\right)
$$


The testing is performed sequentially for $r=0, \ldots \ldots, n-1$ and it terminates when the null hypothesis is not rejected for the first time.

To identify, estimate and test for the number of common trends among the group of the examined stock markets we use the Gonzalo and Granger (1995) methodology, assuming that the common trends are a linear combination of $\mathrm{X}_{t}$, in the form $f_{t}=a_{\perp}^{\prime} X_{t}$. Gonzalo and Granger propose the decomposition of any cointegrating system into its permanent and transitory $(\mathrm{P}-\mathrm{T})$ components:

$$
X_{t}=A_{1} f_{t}+A_{2} z_{t}
$$

where, $z_{t}=\beta^{\prime} X_{t}, A_{1}=\beta_{\perp}\left(\alpha_{\perp}^{\prime} \beta_{\perp}\right)^{-1}$ and $A_{2}=\alpha\left(\beta^{\prime} a\right)^{-1}$. The MLE of $\alpha_{\perp}$ is derived by the eigenvectors which correspond to the $\mathrm{n}-\mathrm{r}$ smallest eigenvalues of the problem

$$
\left|\lambda S_{00}-S_{01} S_{11}^{-1} S_{10}\right|=0
$$

Solving equation (8) for eigenvalues $1>\hat{\lambda}_{1}>\cdots>\hat{\lambda}_{n}>0$ and eigenvectors $\hat{M}=\left(\hat{m}_{1}, \ldots, \hat{m}_{n}\right)$ normalized such that $\hat{M}^{\prime} S_{00} \hat{M}=I$, we get the MLE of $\alpha_{\perp}$ as $\hat{\alpha}_{\perp}=\left(\hat{m}_{r+1} \ldots \hat{m}_{n}\right)$.

One of the advantages of this decomposition is that one can test whether or not certain linear combinations of $\mathrm{X}_{t}$ can be common factor. The null hypotheses on $\alpha_{\perp}$ is:

$$
\mathrm{H}_{0}: \underset{n \times q}{\alpha_{\perp}}=\underset{n \times m}{G} \underset{m \times q}{\theta}
$$


with $\mathrm{q}=\mathrm{n}-\mathrm{r}$ and $q \leq m \leq n$. Under the hypotheses $\mathrm{H}_{0}: \underset{n \times q}{\alpha_{\perp}}=\underset{n \times m}{G} \underset{m \times q}{\theta}$, one can find the maximum likelihood estimator of $\alpha_{\perp}$ as follows:

We first solve

$$
\left|\lambda G^{\prime} S_{00} G-G^{\prime} S_{01} S_{11}^{-1} S_{10} G\right|=0
$$

for eigenvalues $1>\hat{\lambda}_{1}^{*}>\cdots>\hat{\lambda}_{m}^{*}>0$, and eigenvectors $\hat{M}=\left(\hat{m}_{1}^{*}, \ldots, \hat{m}_{m}^{*}\right)$, normalized by $\hat{M}^{* \prime}\left(G^{\prime} S_{00} G\right) \hat{M}^{*}=I$. We choose $\hat{\theta}_{m \times(n-r)}=\left(\hat{m}_{(m+1)-(n-r)} \ldots \hat{m}_{m}\right)$ and $\hat{\alpha}_{\perp}=G \hat{\theta}$. The likelihood ratio test statistic of the hypothesis $\mathrm{H}_{0}$ is given by

$$
L=-T \sum_{i=r+1}^{n} \ln \left[\left(1-\hat{\lambda}_{i+(m-n)}^{*}\right) /\left(1-\hat{\lambda}_{i}\right)\right]
$$

The $\mathrm{L}$ - statistic in equation (11) is distributed as $X_{(n-r) \times(n-m)}^{2}$ asymptotically.

\subsection{DCC-GARCH Approach}

In addition we use the Dynamic Conditional Correlation (DCC) ${ }^{3}$ specification recently proposed by Engle (2002) and Engle and Sheppard (2001), in order to estimate the conditional relationships between the examined stock markets in the CEE region and the two developed stock markets (Germany and US). Unlike the previous methodologies we analyze the conditional relationships using returns of the indices. The major advantage of this model is that while it preserves the main features of standard GARCH models it allows for explicit time variation in the conditional covariance and correlation matrix. The extraction of the conditional time varying correlations allows us to examine the short-run dynamics of the series in our sample. It also allows tracing the effects that

\footnotetext{
${ }^{3}$ Analysis of the DCC model is presented on Appendix.
} 
have the crises events, which took place throughout the sample, on the CEE stock markets.

\subsection{Markov SWARCH-L Approach}

The Markov Switcing ARCH-L ${ }^{4}$ model of Hamilton and Susmel (1994) is the final methodology employed in order to study for structural breaks in volatility of the examined markets during the examined sample time horizon. The basic intuition of this model is that the structural break point, which governs the process, is not known a priori as deterministic event but there exist some imperfectly predictable forces that affect the parameters of the model, producing more accurate estimations and forecasts than other conventional models do. Since when we utilizing dummy variables in order to investigate structural break points (i.e. Asian and Russian crises), the analysis is constrained to account only for possible structural shifts that have taken place on the date of crises events. However, this is not the case at all times, since the hypothetical spill over effects may delay for a short period of time. The SWARCH-L methodology overcomes such difficulties and limitations.

\section{Data and preliminary empirical results}

The data consists of closing prices indices for the Czech, Hungarian, Polish, Slovenian, Slovakian, Estonian, Romanian, German and US stock markets. The time period covered in this study is more than ten years (January 1, 1995 - December 25,

\footnotetext{
${ }^{4}$ See on Appendix for details of the Markov Switching ARCH-L model.
} 
2005), while the data frequency ${ }^{5}$ differs according to the methodology used. The local stock price indices were used for each of the examined CEE stock markets (WIG (Poland), BUX (Hungary), PX50 (Czech Republic), SBI (Slovenia), SAX12 (Slovakia), OMXT (Estonia), BET (Romania)). Moreover, the S\&P500 index is used to represent the US equity market and the DAX for the German market. All the indices are used in local currency terms ${ }^{6}$ and the source of the data is the Datastream.

Table 2 reports the correlation coefficients between the examined market returns. As expected the correlation coefficients are relatively low between the most of the examined markets. The highest values (over 0.50 ) of the correlation coefficients are observed between the three Vysegrad countries (Czech Republic, Hungary, Poland). Finally, regarding the two developed markets (Germany and US) the CEE markets appeared to be more correlated with the German market than the US market, with the exception of Slovakia which is slightly more correlated with the US stock market. In addition, Table 3 provides the descriptive statistics of the weekly index returns. As expected with emerging equity markets, the index returns series are negatively skewed (with the exception of Romania and Slovakia) and leptokurtic.

\footnotetext{
${ }^{5}$ Daily and weekly data used on the cointegration - common trend methodologies, while the DCC model estimates weekly observations and the SWARCH-L model is estimated using daily data.

${ }^{6}$ Expressing the stock price indices in their national currencies restricts their changes to the movements in the stock prices solely, avoiding distortions induced by numerous devaluations of the exchange rates that have taken place in the CEE region (Voronkova (2003)).
} 


\section{Empirical results}

\subsection{Cointegration and common trends results}

The first task here is to determine whether the used series are integrated of order one I(1). For this reason, a battery ${ }^{7}$ of unit root and stationarity tests is implemented. The unit root results are presented in Table 4 and strongly confirm at the 5\% significance level that the stock index series are not stationary in levels, but are stationary in first differences.

Based on these results we proceed with the cointegration and common trend analysis, applying the methodologies described previously. We first select the lag length, $k$, in equation (2), by setting up a separate VECM for each group of markets and using the likelihood ratio test. Further, to determine which sub-model describes best each group of markets, we tested each other using the likelihood ratio tests in Johansen $(1995)^{8}$. We first applied the Johansen's cointegration methodology on the 9-dimensional system of markets (Czech Republic, Hungary, Poland, Slovakia, Slovenia, Estonia, Romania, Germany, US), and as reported in Table 5 there are 3 cointegration relations and 6 common trends respectively. Clearly, the results ${ }^{9}$ indicate that between the examined group of markets there are more common trends than cointegrating relations in its respective VECM. Moreover, we tested for cointegration in three sub-groups, namely the five central European markets (Czech Republic, Hungary, Poland, Slovakia, Slovenia) together with the two developed markets, and the Estonian and Romanian markets with

\footnotetext{
${ }^{7}$ The Augmented Dickey-Fuller, the Phillips-Perron, and Kwiatkowski, Phillips, Schmidt, and Shin tests are implemented and provide the same results.

${ }^{8}$ Johansen (1995, Chapter 11, Corollary 11.2 and Theorem 11.3, pp. 161-162) defines a number of submodels of the general model (2), under the assumption of cointegration and with successive restrictions on the deterministic part of the model $(\mu)$. We tested the five sub-models against each other using the likelihood ratio tests and concluded that the second model, in which there are no trends but a constant term is allowed in the cointegration relations, describes best the examined groups of markets.

${ }^{9}$ Similar are the results using daily data.
} 
the two developed markets respectively. The trace statistics in Table $\mathrm{X}^{10}$ indicate that there are 2 cointegration relations in the first sub-group, while we cannot establish any robust cointegrating vector on the other two sub-groups. The group of markets that appeared to be more integrated, having two cointegrating relations, is the first group of markets, in which are included the four largest markets in the CEE region in terms of market capitalization (Czech, Hungarian, Polish and Slovenian markets). In Table 6 we report the adjustment coefficients for the groups of markets we detected cointegration relations. The statistical significance of all of them indicates that no one of the markets included in the two groups dominate the existing common trends.

Following the methodology proposed by Gonzalo and Granger (1995) we decompose each group of markets into its permanent and transitory components and we analyze the common stochastic trends, in order to see which market or group of markets, if any, contribute significantly to them (are dominant forces). In Table 7 we provide estimates of the linear combinations $\left(\hat{\alpha}_{\perp}\right)^{11}$ that enter each of the common trends for the examined groups of markets. Moreover, Figures 2 and 3 show the P-T decomposition, based on equation (7), for each of the groups of the examined stock markets. These plots are informative in two ways, they refer to the same number of common trends as identified by the trace test and they reveal information as to which market's permanent components are important. The analysis of the plots reveal that in the group where all the CEE markets are included the permanent components are important for the markets of Czech Republic, Hungary, Poland, Slovakia, Slovenia, Germany and US. In order to test

\footnotetext{
${ }^{10}$ The trace statistics for the 3 dimensional systems of markets (i.e Est-Ge-US, Rom-GE-US are not reported here to save space, but are available upon request).

${ }^{11}$ The elements of $\hat{\alpha}_{\perp}$ are coefficients to the common trends which indicates the relative importance of the trend to the market.
} 
the hypothesis that these markets have a common permanent component among the six I(1) country factors we constructed the G matrix in the following form:

$$
G=\left(\begin{array}{lllllll}
1 & 0 & 0 & 0 & 0 & 0 & 0 \\
0 & 1 & 0 & 0 & 0 & 0 & 0 \\
0 & 0 & 1 & 0 & 0 & 0 & 0 \\
0 & 0 & 0 & 1 & 0 & 0 & 0 \\
0 & 0 & 0 & 0 & 1 & 0 & 0 \\
0 & 0 & 0 & 0 & 0 & 1 & 0 \\
0 & 0 & 0 & 0 & 0 & 0 & 1 \\
0 & 0 & 0 & 0 & 0 & 0 & 0 \\
0 & 0 & 0 & 0 & 0 & 0 & 0
\end{array}\right)
$$

where the number of rows is determined by the dimension of the system ( 9 stock markets, namely Czech Republic, Hungary, Poland, Slovakia, Slovenia, Germany, US, Estonia, Romania) and the number of columns ${ }^{12}$ is determined by the number of markets with a significant permanent component (7 in this case). In Table 8 are reported the L-statistics for the hypotheses tested. As indicated, this null hypothesis is accepted at the 5 percent significance level. Thus, there is evidence that the five central European stock markets (Czech Republic, Hungary, Poland, Slovakia, Slovenia) together with the German stock market and the US stock market have a significant common permanent component, which drives this system of stock exchanges in the long run. Contrary, the Estonian and the Romanian stock markets are segmented from this system, a finding that confirms the results in cointegration analysis. We test also the hypothesis that all the markets except for Romania, Estonia and the smallest market in central Europe-Slovakia have a common permanent component, which is rejected. We reject also the hypothesis that all the CEE markets alone have a common permanent component. Moreover, regarding the group of the central European stock markets and the two developed markets we test the hypothesis that the three bigger markets in the region (Czech Republic, Hungary, Poland) together

\footnotetext{
${ }^{12}$ The number of columns depends on the hypothesis tested and can range between $\mathrm{q}=6$ and $\mathrm{n}=9$, see equation (9).
} 
with the German and the US markets have a common permanent component. The last hypothesis is also rejected.

Figure 4 displays the demeaned transitory components for the sample of equity markets. For the majority of the markets while significant deviations (i.e Russian crisis period) from the common trends do occur, they are short-lived. For the Estonian and Romanian markets however, the pattern is quite different, since there would appear to be relatively more volatilite in the transitory components, confirming the results of the Gonzalo and Granger test. Moreover, the deviation from the common trends through the Russian crisis period is bigger and longer for these two markets.

\subsection{DCC-GARCH results}

After having examined the long - run relationships between the stock markets in the CEE region we applied a bivariate DCC-GARCH(1,1) model to study the short - run interdependencies between the examined markets, as well as the effects that have the crises events, which took place throughout the sample, on the CEE stock markets. As expected the conditional correlation coefficients are relatively low between the most of the examined markets, while we can observe an increasing trend on the conditional correlation (CC) among the 3 biggest CEE markets (Czech Republic, Hungary, Poland) with the German and the US markets. What is also evident is the change in the pattern of conditional correlations through the period between 1997 and 1999. As emerges from Figure 5, during the period of Asian crisis (summer of 1997) the correlations between the CEE markets and the developed markets, especially with Germany, raised dramatically. In the second half of 1997, as the crisis was unfolding, the short term dependences 
weakened, reflecting in falling conditional correlations (i.e. Czech Republic-Germany, Poland- Germany). A second and much more significant rise in conditional correlations with both the German and the US markets followed at the mid of 1998, when the Russian crisis took place. For example the $\mathrm{CC}$ between the Czech and the German market increased from 0.02 before the summer of 1998 to 0.56 at the end of November of 1998 . After the Russian crisis we observe a sharp decline in the intensity of the co-movements (i.e. Slovenia-Germany, Czech-US, Czech-Germany) as the events in the domestic markets started to dominate influences from outside. In some cases (i.e. HungaryGermany, Poland-Germany), after the Russian crisis the CC did not decline sharply, but declined little by little since then. Another rise, but significantly lower for the most of the examined markets, in CC is observed on 2001 (i.e. Czech-Germany, Estonia-Germany, Estonia-US, Romania-US), when the most of the markets all over the world respond simultaneously to the terrorist attacks in US.

Thus the DCC analysis suggests that the short - term interdependencies between the CEE stock markets and the developed stock markets are affected mostly by crises in other emerging market regions and particularly is the Russian crisis that appeared to have the biggest impact on the conditional correlations between the CEE markets and the developed markets. Moreover, the conditional correlations between the three bigger markets in the CEE region (Czech Republic, Hungary, Poland) and the two developed markets rose dramatically through the period of the two crises (Asian and Russian crises) and remained at a significantly higher level until the end of the examined period. Contrary, the CC between the rest of the CEE markets and the developed markets, despite 
some significant spikes they have through the crises periods, they appeared not to have any permanent impact from the crises since they return to their initial low levels.

\subsection{Markov SWARCH-L results}

The application of the DCC methodology reveals that during the examined period there are some events like the Russian crisis that appeared to have a significant impact on the conditional correlations between the CEE markets and the developed markets. In consistence with Rigobon and Forbes (2002) who argue that the increased correlations over crises periods are due to an increase in volatility in world markets because of the crisis, we apply the Markov Switching ARCH-L (SWARCH-L) model of Hamilton and Susmel (1994) to study for structural breaks in volatility of the examined markets during the examined period. Figure 6 displays the time-varying probabilities of volatility levels (low, medium, high), for the examined CEE stock markets. From the analysis of the plots it is revealed that the conditional volatility has increased (over 200\%) during the Russian crisis, for all the CEE markets. While it is the Czech and Estonian markets that appear to have the more immediate impact on conditional volatility during the Russian crisis period, confirming the results from the DCC analysis. Moreover, significant is the increase in conditional volatility level for the Estonian market on September 2001 when the terrorist attack in US took place. The last finding is also consistent with the big spike in conditional correlation between the Estonian and the German and US markets. 


\section{Summary and concluding remarks}

The present paper examined the short- and long term relationships between seven Central Eastern European stock markets (Czech Republic, Poland, Hungary, Slovakia, Slovenia, Estonia and Romania) and 2 developed stock markets, namely the German and the US markets. The case of integration among the markets in our sample is examined in this study using the methodology of cointegration and common trends analysis. We applied the Gonzalo and Granger (1995) methodology to identify, estimate and test for the number of common trends among the group of the examined stock markets. We also use the recent Dynamic Conditional Correlation (DCC) specification proposed by Engle (2002) and Engle and Sheppard (2001), in order to estimate the conditional relationships between the examined stock markets in the CEE region and the two developed stock markets. Moreover, we applied the Markov Switching ARCH-L (SWARCH-L) model of Hamilton and Susmel (1994) to study for structural breaks in volatility of the examined markets during the examined period.

Our results, based on daily and weekly data during the period 1995-2005, indicate that the examined stock markets are partially integrated, since they have more common trends than cointegrating relations that bind them together in the long run. There is also evidence that the five stock markets in Central Europe (Czech Republic, Hungary, Poland, Slovenia and Slovakia) together with the German and the US stock markets have a significant common permanent component, which drives this system of stock exchanges in the long run. Contrary, the Estonian and Romanian markets are segmented from this sub-group of markets. This finding is consistent with the higher and more 
significant deviations of the transitory components from the common trends in these two markets.

Our results lead to the argument that the investor's benefits from diversifying into the Central Eastern European equity markets are reduced, since the level of integration among the markets in CEE region and the developed markets (Germany, US) is higher ${ }^{13}$, particularly between the five markets in central Europe (Czech Republic, Hungary, Poland, Slovenia and Slovakia) and the developed markets, where we found a significant common permanent component, which drives this system of stock exchanges in the long run. In contrast, the application of portfolio diversification strategies on the Estonian and Romanian markets is more profitable, since they appeared to be segmented from this system of stock exchanges. Moreover, there is no sign of cointegration relation between these two markets and the two developed markets. In the short-run also exist diversification benefits for these two markets, since there are significant deviations from the common trends and the conditional correlations, despite some significant spikes during some crises events (Russian crisis), remain in low levels. Reduced are the shortterm benefits for the bigger markets (Czech, Hungary, Poland) since there are no many significant deviations from the common trends and the conditional correlations have been considerably increased, through the examined period. Overall these findings indicate that among the CEE markets there are two sub-groups (Czech Republic, Hungary, Poland, Slovenia and Slovakia) and (Estonia and Romania) that have to be considered as separate classes of assets in asset allocation decisions.

\footnotetext{
${ }^{13}$ Comparing with a number of earlier studies which failed to detect any cointegration relationship between the CEE markets and the developed markets.
} 
Therefore, as the economies of Central Eastern European states become more integrated with the developed economies, on the way to join the European Monetary Union, the examination of possible increasing long-run interdependencies and comovements of these markets with major international stock markets will remain a crucial issue for both academic researchers and portfolio managers. Thus, further research is required to shed more light into this important topic. 


\section{REFERENCES}

Bekaert, G. and C. R. Harvey (1995), “Time-Varying World Market Integration”, The Journal of Finance 50(2) 403-444

Bekaert, G. and C. R. Harvey (1997), "Emerging Equity Market Volatility”, Journal of Financial Economics 43, 29-4

DeFusco, R.A., Geppert, J.M., Tsetsekos, G., (1996). "Long-run diversification potential in emerging stock markets". Financ. Rev., 31, 343-363.

Egert B. and E. Kocenda (2005), "Contagion across and integration of Central and Eastern European stock markets: Evidence from intraday data", William Davinson Institute, Working paper, 798.

Engle, R. and K. Sheppard, (2001), "Theoretical and Empirical properties of Dynamic Conditional Correlation Multivariate GARCH”, NBER Working Paper 8554.

Engle, R.F. (2002), "Dynamic conditional correlation: a new simple class of multivariate GARCH models", Journal of Business and Economic Statistics, 20, 339-350.

Forbes K. and R. Rigobon (2002), "No Contagion, Only Interdependence: Measuring Stock Market Comovements", The Journal of Finance, Vol. 57 Issue 5 Page 2223.

Fraser P. and O. Oyefeso (2005), "US, UK and European stock market integration", Journal of Business Finance \& Accounting, 32 (1)\&(2).

Gelos, G. and R. Sahay (2000), "Financial Market Spillovers in Transition Economies", Economics of Transition 9(1), 53-86.

Georgoutsos, D.A. and G.P. Kouretas (2001), "Common Stochastic Trends in International Stock Markets: Testing in an Integrated Framework", University of Crete Working Paper (http://www.dbase-soc-uoc.gr/ewp/ papers/cst.pdf).

Gilmor C.G., McManus G.M. (2002), "International Portfolio diversification: US and Central European Equity Markets”, Emerging Markets Review, 3, 69-83.

Gonzalo J, Granger CWJ (1995), "Estimation of common long-memory components in cointegrated systems". Journal of Business and Economic Statistics, 13, 27-35.

Hamilton James D., and Susmel R. (1994),“Autoregressive conditional heteroskedasticity and changes in regime”, Journal of Econometrics, 64, 307-333.

Johansen S (1995), "Likelihood-based inference in cointegrated vector autoregressive models". Oxford University Press, Oxford. 
Johansen S, Juselius K (1990), "Maximum likelihood estimation and inference on cointegration with applications to the demand for money". Oxford Bulletin of Economics and Statistics, 52, 169-210

Johansen, S. (1988), "Statistical Analysis of Cointegrating Vectors", Journal of Economics Dynamics and Control, 12, 231-254.

Kasa, K., (1992). "Common stochastic trends in international stock markets". J. Monetary Econ. 29, 95-124.

Linne, T. (1998), "The Integration of the Central and Eastern European Equity Markets into the International Capital Markets", Institut für Wirtschaftsforschung Halle Working Paper 1/1998

Phylaktis, K. and Ravazzolo, Fabiola (2002), "Stock Market Linkages in Emerging Markets: Implications for International Portfolio Diversification", Journal of International Financial Markets, Institutions and Money, 15, 2, 91-106.

Röckinger, M. and G. Urga (2001), "A Time-Varying Parameter Model to Test for Predictability and Integration in the Stock Markets of Transition Economies", Journal of Business \& Economic Statistics, 19(1), 73-84.

Scheicher M. (2001), "The comovements of $t$ Stock Markets in Hungary, Poland and the Czech Republic", International Journal of Finance and Economics, 6, 27-39.

Schotman P. and A. Zalewska (2005). "Non-synchronous trading and testing for market integration in central European emerging markets", CEPR, Discussion papers.

Spyrou, S., Garret, I. (1999), "Common Trends in the Emerging Equity Markets", The Manchester School, 67(6), 649-660.

Voronkova, S., 2003. "Instability in the long-run relationships: Evidence from the Central European emerging stock markets". Discussion Paper. Symposium on International Equity Market Integration, Institute for International Integration Studies, Dublin. 


\section{APPENDIX}

\section{SWARCH-L model $^{14}$}

$y_{t}:$ observed returns

$S_{t}$ : latent variable-unobserved random variable of the form $S_{t}=\left\{\begin{array}{l}1 \\ 2 \\ 3\end{array}\right.$

The latent variable $S_{t}$ corresponds to the "state" or "Regime" that the ARCH process is at time t and can be described by a M arkov Chain, as follow s:

$\mathrm{P}\left(\mathrm{S}_{\mathrm{t}}=j \mid \mathrm{S}_{\mathrm{t}-1}=i, \ldots, y_{t-1}, y_{t-1}, \ldots\right)=\mathrm{P}\left(\mathrm{S}_{\mathrm{t}}=j \mid \mathrm{S}_{\mathrm{t}-1}=i\right)$ for $\mathrm{i}, \mathrm{j}=1,2,3$

The transition matrix $P\left\{\mathrm{p}_{\mathrm{ij}}\right\}$ of the above states is given below:

$\mathrm{P}=\left(\begin{array}{lll}p_{11} & p_{21} & p_{31} \\ p_{12} & p_{22} & p_{32} \\ p_{13} & p_{23} & p_{33}\end{array}\right)$ with $\sum_{\mathrm{j}}^{3} \mathrm{p}_{\mathrm{ij}}=1$

For reasons of simplicity we restrict our analysis so as not to allow state 2 to come after state $1\left(p_{21}=0\right)$, and state 1 to com e after state $3\left(p_{13}=0\right)$.

$\mathrm{P}=\left(\begin{array}{ccc}p_{11} & 0 & p_{31} \\ p_{12} & p_{22} & p_{32} \\ 0 & p_{23} & p_{33}\end{array}\right)$

M ean equation: $\mathrm{y}_{\mathrm{t}}=\phi_{0}+\phi_{1} \mathrm{y}_{\mathrm{t}-1}+u_{t}$

$u_{t}=\sqrt{g_{s_{t}} \cdot w_{t}}$

$u_{t}=\sqrt{g_{1} \cdot w_{t}}$ or $u_{t}=\sqrt{g_{2} \cdot w_{t}}$ or $u_{t}=\sqrt{g_{3} \cdot w_{t}}$ where $g_{1}$ is normalized to unity

$\mathrm{w}_{\mathrm{t}} \square$ A R C H - L (2) process i.e. $\mathrm{w}_{\mathrm{t}}=\mathrm{z}_{t} \cdot \sqrt{h_{t}}, \mathrm{z}_{\mathrm{t}} \square \sim$ Student $-t(d . f)$

$h_{t}=a_{0}+a_{1} \cdot w_{t-1}^{2}+a_{2} \cdot w_{t-2}^{2}+\xi \cdot w_{t-1}^{2}$, resulting in 13 parameters for estimation.

\section{DCC model}

The Engle's (2002) DCC model can be formulated as the following

statistical specification:

$r_{t} \mid \tilde{S}_{t-1} \square N\left(0, D_{t} R_{t} D_{t}\right)$

$D_{t}^{2}=\operatorname{diag}\left\{\omega_{i}\right\}+\operatorname{diag}\left\{k_{i}\right\} \circ r_{t-1} r_{t-1}^{\prime}+\operatorname{diag}\left\{\lambda_{i}\right\} \circ D_{t-1}^{2}$

$\varepsilon_{t}=D_{t}^{-1} r_{t}$

$Q_{t}=S \circ\left(u \imath^{\prime}-A-B\right)+A \circ \varepsilon_{t-1} \varepsilon_{t-1}^{\prime}+B \circ Q_{t-1}$

$R_{t}=\operatorname{diag}\left\{Q_{t}\right\}^{-1} Q_{t} \operatorname{diag}\left\{Q_{t}\right\}^{-1}$

where $l$ is a vector of ones and $\circ$ is the Hadamard product of two identically sized matrices

which is computed simply by element by element multiplication.

They show that if $\mathrm{A}, \mathrm{B}$ and $\left(\iota \iota^{\prime}-A-B\right)$ are positive semi-definite, then $\mathrm{Q}$ will be positive semi definite.

If any one of the matrices is positive definite, then $Q$ will also be.

The assumption of normality in the first equation gives rise to a likelihood function.

The second equation simply expresses the assumption that each of the assets follows a univariate GARCH process.

The log likelihood for this estimator can be expressed as:

$r_{t} \mid \tilde{S}_{t-1} \square N\left(0, H_{t}\right)$

$L=-\frac{1}{2} \sum_{t=1}^{T}\left(n \log (2 \pi)+2 \log \left|D_{t}\right|+r_{t}^{\prime} D_{t}^{-1} D_{t}^{-1} r_{t}-\varepsilon_{t}^{\prime} \varepsilon_{t}+\log \left|R_{t}\right|+\varepsilon_{t}^{\prime} R_{t}^{-1} \varepsilon_{t}\right)$

${ }^{14}$ Tables with the estimated variables of the SWARCH-L and DCC models are available upon request 
Table 1: Market Characteristics for CEE stock exchanges

\begin{tabular}{|c|c|c|c|c|c|c|c|c|c|c|c|c|}
\hline \multicolumn{13}{|c|}{ Market Capitalization - Number of firms } \\
\hline & \multicolumn{2}{|c|}{1995} & \multicolumn{2}{|c|}{1998} & \multicolumn{2}{|c|}{2000} & \multicolumn{2}{|c|}{2002} & \multicolumn{2}{|c|}{2003} & \multicolumn{2}{|c|}{2004} \\
\hline & M.C. & $\begin{array}{c}\mathrm{N}^{\mathrm{o}} \\
\text { Firms }\end{array}$ & M.C. & $\begin{array}{c}\mathrm{N}^{\circ} \\
\text { Firms }\end{array}$ & M.C. & $\begin{array}{c}\mathrm{N}^{\circ} \\
\text { Firms }\end{array}$ & M.C. & $\begin{array}{c}\mathrm{N}^{\circ} \\
\text { Firms }\end{array}$ & M.C. & $\begin{array}{c}\mathrm{N}^{\circ} \\
\text { Firms }\end{array}$ & M.C. & $\begin{array}{c}\mathrm{N}^{\circ} \\
\text { Firms }\end{array}$ \\
\hline $\begin{array}{c}\text { Czech } \\
\text { Republic }\end{array}$ & 17.71 & 1698 & 13.43 & 283 & 11.34 & 142 & 15.86 & 79 & 25.13 & 65 & 35.82 & 55 \\
\hline Estonia & N.A. & N.A. & N.A. & N.A. & 1.87 & 25 & 1.74 & 17 & 2.93 & 16 & 5.45 & 17 \\
\hline Hungary & 2.35 & 42 & 13.79 & 55 & 11.92 & 60 & 13.09 & 49 & 16.69 & 53 & 24.57 & 54 \\
\hline Poland & 4.56 & 65 & 20.70 & 198 & 31.42 & 225 & 28.79 & 216 & 44.84 & 203 & 97.56 & 230 \\
\hline Romania & 0.10 & 9 & 0.36 & 126 & 0.41 & 114 & 2.73 & 65 & 3.74 & 62 & 11.94 & 60 \\
\hline Slovakia & 5.35 & N.A. & 4.12 & 833 & 3.27 & 866 & 2.62 & 510 & 3.33 & 448 & 4.10 & 389 \\
\hline Slovenia & 0.80 & 26 & 4.41 & 92 & 5.01 & 154 & 9.83 & 139 & 12.89 & 136 & 15.12 & 142 \\
\hline
\end{tabular}

Table 2: Correlation coefficients of weekly stock return series

\begin{tabular}{|c|c|c|c|c|c|c|c|c|c|}
\hline & Czech & Estonia & Germany & Hungary & Poland & Romania & Slovakia & Slovenia & US \\
\hline Czech & 1.00 & 0.23 & 0.38 & 0.58 & 0.53 & 0.23 & 0.08 & 0.23 & 0.29 \\
\hline Estonia & 0.23 & 1.00 & 0.25 & 0.20 & 0.25 & 0.12 & 0.06 & 0.13 & 0.13 \\
\hline Germany & 0.38 & 0.25 & 1.00 & 0.48 & 0.47 & 0.01 & 0.05 & 0.13 & 0.72 \\
\hline Hungary & 0.58 & 0.20 & 0.48 & 1.00 & 0.62 & 0.14 & 0.14 & 0.34 & 0.39 \\
\hline Poland & 0.53 & 0.25 & 0.47 & 0.62 & 1.00 & 0.14 & 0.08 & 0.24 & 0.44 \\
\hline Romania & 0.23 & 0.12 & 0.01 & 0.14 & 0.14 & 1.00 & 0.03 & 0.18 & 0.01 \\
\hline Slovakia & 0.08 & 0.06 & 0.05 & 0.14 & 0.08 & 0.03 & 1.00 & 0.06 & 0.07 \\
\hline Slovenia & 0.23 & 0.13 & 0.13 & 0.34 & 0.24 & 0.18 & 0.06 & 1.00 & 0.07 \\
\hline US & 0.29 & 0.13 & 0.72 & 0.39 & 0.44 & 0.01 & 0.07 & 0.07 & 1.00 \\
\hline
\end{tabular}

Table 3: Descriptive statistics of weekly index return series

\begin{tabular}{|c|c|c|c|c|c|c|c|c|c|}
\hline & $\mathrm{Cz}$ & $\mathrm{Est}$ & $\mathrm{Ge}$ & $\mathrm{Hu}$ & $\mathrm{Pol}$ & $\mathrm{Ro}$ & $\mathrm{Slk}$ & Slv & US \\
\hline Mean & 0.002 & 0.001 & 0.001 & 0.002 & 0.001 & 0.004 & 0.002 & 0.003 & 0.001 \\
\hline Median & 0.005 & 0.002 & 0.003 & 0.004 & 0.001 & 0.003 & 0.000 & 0.003 & 0.002 \\
\hline Maximum & 0.116 & 0.191 & 0.129 & 0.147 & 0.120 & 0.245 & 0.188 & 0.064 & 0.075 \\
\hline Minimum & -0.140 & -0.249 & -0.141 & -0.330 & -0.192 & -0.214 & -0.097 & -0.119 & -0.123 \\
\hline Std. Dev. & 0.030 & 0.044 & 0.035 & 0.043 & 0.035 & 0.047 & 0.032 & 0.019 & 0.025 \\
\hline Skewness & -0.332 & -1.177 & -0.228 & -1.290 & -0.495 & 0.114 & 0.645 & -0.567 & -0.493 \\
\hline Kurtosis & 4.601 & 11.433 & 4.427 & 12.863 & 6.152 & 6.525 & 6.296 & 7.853 & 5.424 \\
\hline & & & & & & & & & \\
\hline Jarque-Bera & 53.425 & 1363.864 & 39.933 & 1849.272 & 194.136 & 221.943 & 222.931 & 441.935 & 121.840 \\
\hline Probability & 0.000 & 0.000 & 0.000 & 0.000 & 0.000 & 0.000 & 0.000 & 0.000 & 0.000 \\
\hline
\end{tabular}


Table 4: Unit root tests

\begin{tabular}{|c|c|c|c|c|c|c|}
\hline \multicolumn{7}{|c|}{ Log Levels } \\
\hline & \multicolumn{2}{|c|}{ ADF } & \multicolumn{2}{|c|}{$\mathbf{P P}$} & \multicolumn{2}{|c|}{ KPSS } \\
\hline Market & trend & constant & trend & constant & trend & constant \\
\hline Czech & -1.07 & 1.03 & -1.24 & 0.66 & $0.51 *$ & $1.54 *$ \\
\hline Hungary & -1.59 & 0.05 & -1.79 & -0.17 & $0.41 *$ & $1.58 *$ \\
\hline Poland & -1.72 & -0.31 & -1.88 & -0.51 & $0.40^{*}$ & $1.29 *$ \\
\hline Slovenia & -1.60 & -0.15 & -1.81 & -0.25 & $0.41 *$ & $2.42 *$ \\
\hline Slovakia & -2.27 & 1.13 & -2.26 & 1.13 & $0.53 *$ & $1.70^{*}$ \\
\hline Estonia & $-3.99 *$ & -0.03 & $-3.83 *$ & -0.43 & $0.50 *$ & $1.67 *$ \\
\hline Romania & -3.03 & 1.34 & -2.99 & 0.98 & $0.50 *$ & $2.27 *$ \\
\hline Germany & -1.68 & -1.45 & -1.72 & -1.48 & $0.28^{*}$ & $0.92 *$ \\
\hline US & -2.02 & -1.94 & -1.92 & -1.85 & $0.29 *$ & $0.45^{* *}$ \\
\hline \multicolumn{7}{|c|}{ 1st differences } \\
\hline Czech & $-18.72 *$ & $-18.50^{*}$ & $-18.71 *$ & $-18.63 *$ & 0.05 & $0.50 *$ \\
\hline Hungary & $-12.62 *$ & $-12.53^{*}$ & $-21.95^{*}$ & $-21.87^{*}$ & 0.03 & 0.23 \\
\hline Poland & $-21.22 *$ & $-21.13^{*}$ & $-21.24 *$ & $-21.16^{*}$ & 0.04 & 0.25 \\
\hline Slovenia & $-9.32 *$ & $-9.32 *$ & $-19.38^{*}$ & $-19.40^{*}$ & 0.11 & 0.13 \\
\hline Slovakia & $-20.92 *$ & $-20.32 *$ & $-20.93 *$ & $-20.35^{*}$ & 0.07 & 1.28 \\
\hline Estonia & $-17.93 *$ & $-17.42 *$ & $-18.00^{*}$ & $-17.70^{*}$ & 0.11 & $0.89 *$ \\
\hline Romania & $-18.60^{*}$ & $-18.30 *$ & $-18.67 *$ & $-18.47 *$ & 0.09 & $0.67 *$ \\
\hline Germany & $-19.59 *$ & $-19.62 *$ & $-19.58^{*}$ & $-19.60 *$ & $0.16^{*}$ & 0.16 \\
\hline US & $-22.65^{*}$ & $-22.67 *$ & $-22.68 *$ & $-22.70 *$ & $0.16^{*}$ & 0.17 \\
\hline
\end{tabular}

Notes: ADF, PP, and KPSS are the Augmented Dickey-Fuller, the Phillips-Perron and the Kwiatowski-Phillips-Schmidt-Shin unit root tests, respectively. The lag length is chosen using the Shwartz information criterion for the ADF test, and the Newey West Kernel estimator for the PP and KPSS tests. *, **, denotes the rejection of the null hypothesis at the $5 \%$ and $1 \%$ significance levels respectively. For the ADF and PP tests, the null hypothesis is the presence of a unit root, whereas for the KPSS tests, the null hypothesis is stationarity.

Table 5: Trace Statistics

\begin{tabular}{|c|c|c|c|}
\hline$(\mathbf{n}-\mathbf{r})$ & $\begin{array}{c}\mathbf{7} \text { CEE + } \\
\text { GE, US }\end{array}$ & $\begin{array}{c}\mathbf{5} \text { CEE + GE, } \\
\text { US }\end{array}$ & $\begin{array}{c}\mathbf{5 \%} \text { Critical } \\
\text { Values }\end{array}$ \\
\hline 9 & $243.9836^{*}$ & & 202.92 \\
\hline 8 & $183.6437^{*}$ & & 165.58 \\
\hline 7 & $134.8055^{*}$ & $155.7454^{*}$ & 131.7 \\
\hline 6 & 97.34124 & $108.7634^{*}$ & 102.14 \\
\hline 5 & 65.4435 & 75.24273 & 76.07 \\
\hline 4 & 37.80986 & 45.8048 & 53.12 \\
\hline 3 & 20.26313 & 21.44567 & 34.91 \\
\hline 2 & 9.048943 & 10.01639 & 19.96 \\
\hline 1 & 1.563029 & 1.854004 & 9.24 \\
\hline $\mathrm{k}$ & 10 & 10 & \\
\hline Model & $\mathbf{2}^{*}$ & $\mathbf{2}$ & \\
\hline
\end{tabular}

The value reported at the top of each column is for $r=0$, so that $n-r=n$, where $n$ is the number of markets included in each group. * denotes rejection of the null hypothesis of at most $r$ cointegrating relations at the $5 \%$ significance level. $\mathrm{k}$ indicates the lag intervals. 2 indicates the sub model selected according to the likelihood ratio tests, in which there are no trends but a constant term is allowed in the cointegration relations. 
Table 6: Adjustment coefficients

\begin{tabular}{|c|c|c|c|c|c|}
\hline & \multicolumn{3}{|c|}{ 7 CEE + GE, US } & \multicolumn{2}{c|}{ 5 CEE + GE, US } \\
\hline & $\mathrm{a} 1$ & $\mathrm{a} 2$ & $\mathrm{a} 3$ & $\mathrm{a} 1$ & $\mathrm{a} 2$ \\
\hline Czech & $-0.117^{*}$ & $-0.004^{*}$ & $-0.069^{*}$ & $-0.108^{*}$ & $-0.080^{*}$ \\
\hline Estonia & $-0.068^{*}$ & $-0.008^{*}$ & $-0.037^{*}$ & & \\
\hline Germany & $-0.113^{*}$ & $-0.068^{*}$ & $-0.075^{*}$ & $-0.124^{*}$ & $-0.081^{*}$ \\
\hline Hungary & $-0.052^{*}$ & $0.020^{*}$ & $-0.031^{*}$ & $-0.044^{*}$ & $-0.040^{*}$ \\
\hline Poland & $0.002^{*}$ & $0.032^{*}$ & $-0.006^{*}$ & $-0.009^{*}$ & $-0.022^{*}$ \\
\hline Romania & $-0.003^{*}$ & $0.089^{*}$ & $0.006^{*}$ & & \\
\hline Slovakia & $-0.028^{*}$ & $0.049^{*}$ & $0.000^{*}$ & $0.006^{*}$ & $-0.002^{*}$ \\
\hline Slovenia & $-0.036^{*}$ & $-0.002^{*}$ & $-0.020^{*}$ & $-0.031^{*}$ & $-0.021^{*}$ \\
\hline US & $-0.001^{*}$ & $-0.046^{*}$ & $-0.019^{*}$ & $-0.001^{*}$ & $-0.005^{*}$ \\
\hline
\end{tabular}

The superscript denotes the corresponding cointegration relation

Table 7: The estimated $\hat{\alpha}_{\perp} \mathrm{s}$

\begin{tabular}{|c|c|c|c|c|c|c|c|c|c|c|c|}
\hline & \multicolumn{7}{|c|}{ 7 CEE + GE, US } & \multicolumn{5}{|c|}{ 5 CEE + GE, US } \\
\hline & $\hat{\alpha}_{\perp}^{1}$ & $\hat{\alpha}_{\perp}^{2}$ & $\hat{\alpha}_{\perp}^{3}$ & $\hat{\alpha}_{\perp}^{4}$ & $\hat{\alpha}_{\perp}^{5}$ & $\hat{\alpha}_{\perp}^{6}$ & $\hat{\alpha}_{\perp}^{1}$ & $\hat{\alpha}_{\perp}^{2}$ & $\hat{\alpha}_{\perp}^{3}$ & $\hat{\alpha}_{\perp}^{4}$ & $\hat{\alpha}_{\perp}^{5}$ \\
\hline Czech & 21.60 & -30.25 & 3.31 & 1.77 & 6.21 & -6.68 & 10.99 & 21.17 & -13.65 & 3.50 & 2.14 \\
\hline Estonia & -8.26 & -2.09 & 10.27 & 9.52 & 22.03 & -7.58 & & & & & \\
\hline Germany & 10.39 & 32.94 & -3.64 & -4.43 & -10.46 & 3.83 & -17.88 & -23.30 & 15.84 & 0.47 & -6.83 \\
\hline Hungary & -18.27 & -1.80 & 9.15 & 25.01 & -20.14 & 12.45 & -2.36 & 2.33 & -9.34 & -33.13 & -7.16 \\
\hline Poland & 19.52 & 14.40 & 18.07 & -20.26 & 12.79 & 10.75 & 30.56 & -15.50 & 13.13 & 13.42 & 16.09 \\
\hline Romania & 13.72 & -2.06 & -6.24 & 4.34 & -6.36 & -5.23 & & & & & \\
\hline Slovakia & -6.45 & -1.13 & 9.21 & -13.71 & -10.06 & -21.94 & 9.19 & 7.18 & 5.39 & 11.73 & -28.22 \\
\hline Slovenia & -17.08 & -27.22 & -1.95 & -42.44 & -2.13 & 26.83 & -20.00 & 20.90 & -22.65 & 34.31 & 21.60 \\
\hline US & -13.49 & -24.78 & 3.11 & -1.20 & -8.27 & -26.80 & 1.47 & -3.76 & -45.43 & 16.33 & -9.36 \\
\hline
\end{tabular}

The superscript denotes the corresponding common trend. The common trends are based on the normalization $\hat{M}^{\prime} \mathrm{S}_{00} \hat{\mathrm{M}}=\mathrm{I}$.

Table 8: Testing for linear combinations on the common trends

\begin{tabular}{|c|c|c|c|}
\hline $\mathrm{H}_{0}$ & L-stat. & $X_{(n-r) x(n-m)}^{2}$ & $(n-r) \times(n-m)$ \\
\hline \multicolumn{3}{|c|}{ 7 CEE + GE, US } \\
\hline All except for Estonia and Romania & $16.788^{*}$ & 21.02 & 12 \\
\hline All except for Germany and US & 28.23 & 21.02 & 12 \\
\hline All except for Estonia, Romania and Slovakia & 47.64 & 28.86 & 18 \\
\hline \multicolumn{4}{|c|}{ 5 CEE + GE, US } \\
\hline Vysegrad Countries + Germany and US
\end{tabular}

$\mathrm{H}_{0}$ : The respective market or group of markets contributes significantly to the common trend(s). * denotes acceptance of the null hypothesis at the $5 \%$ significance level. 
Figure 1: (Log) Stock Prices
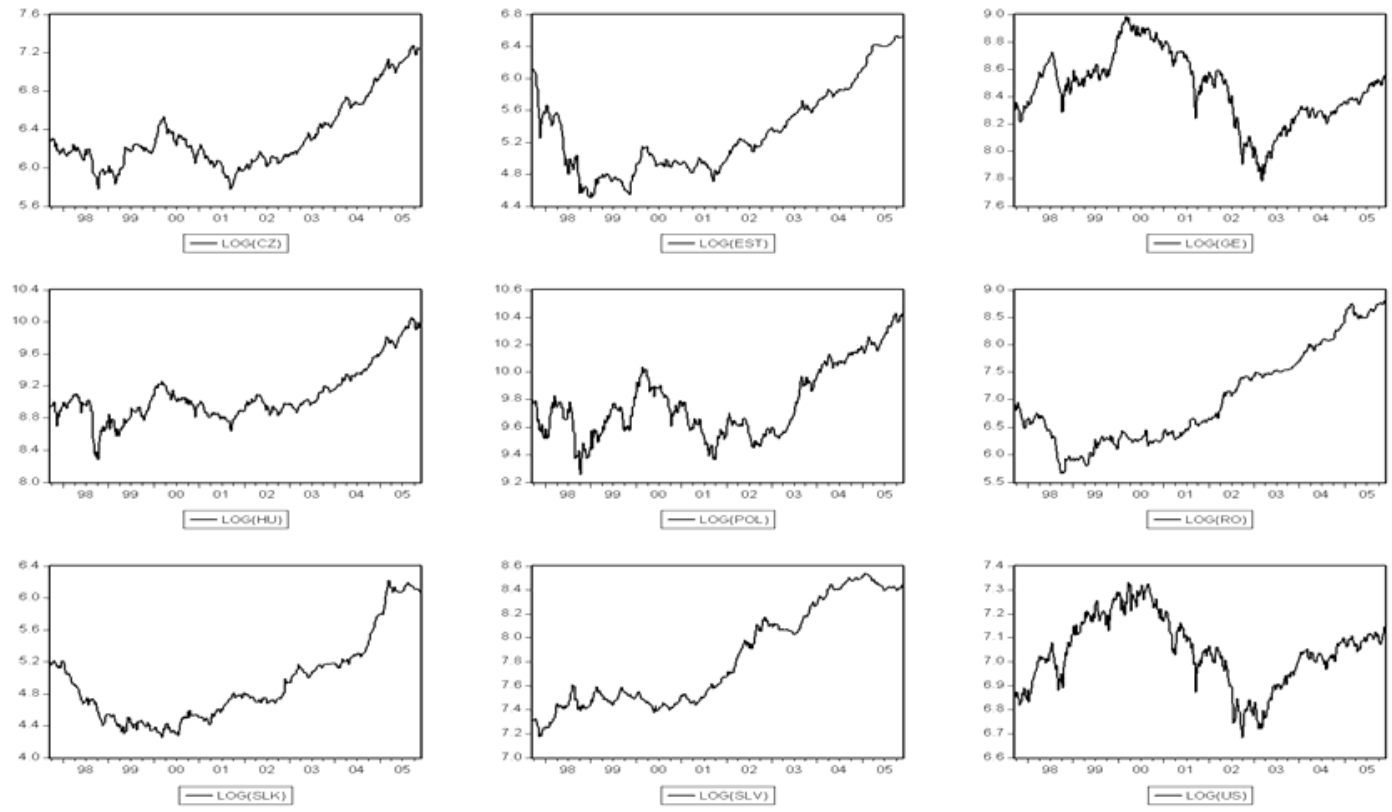

Figures 2 and 3: P-T components decomposition of the two groups of markets

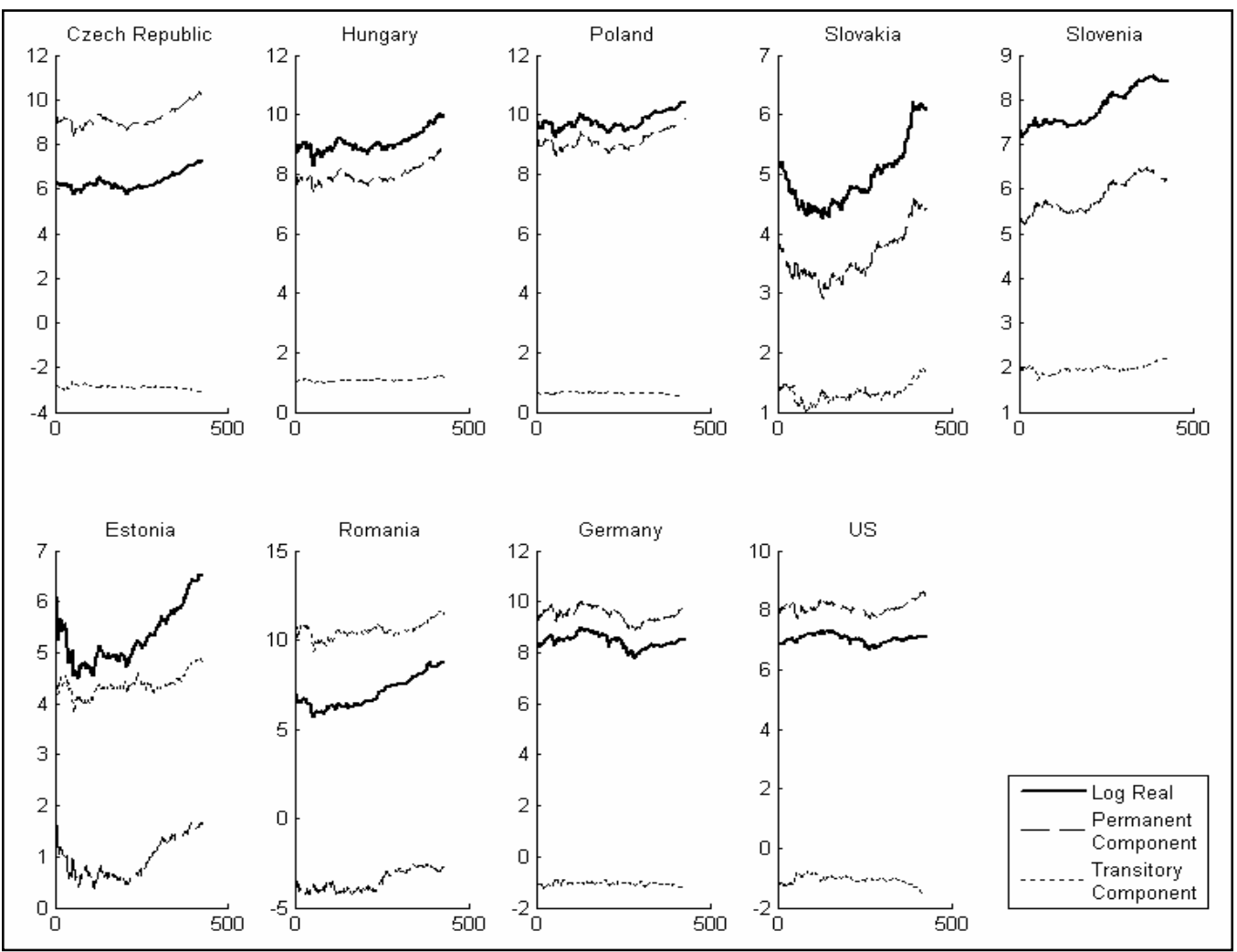




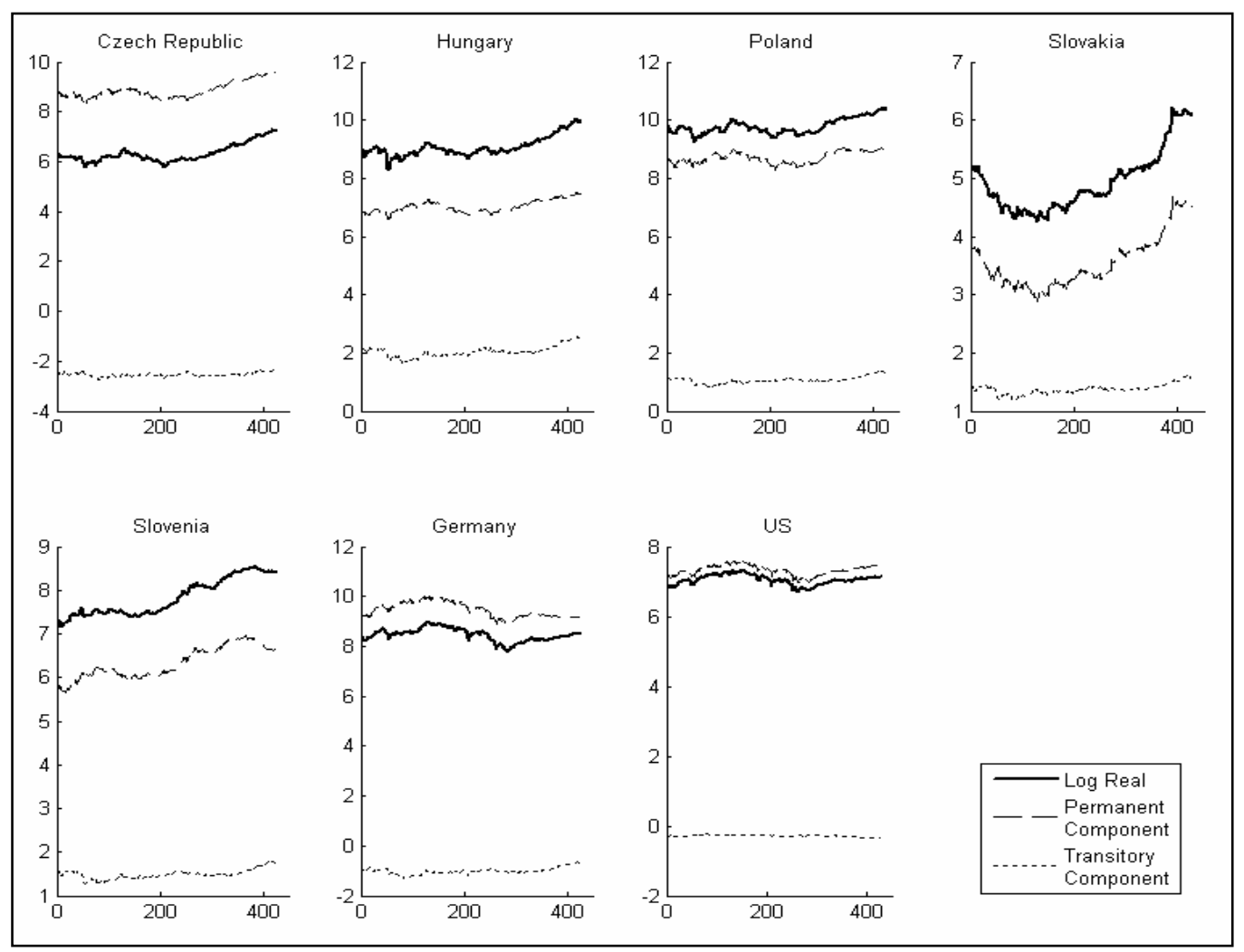

Figures 4: The Transitory component of stock prices

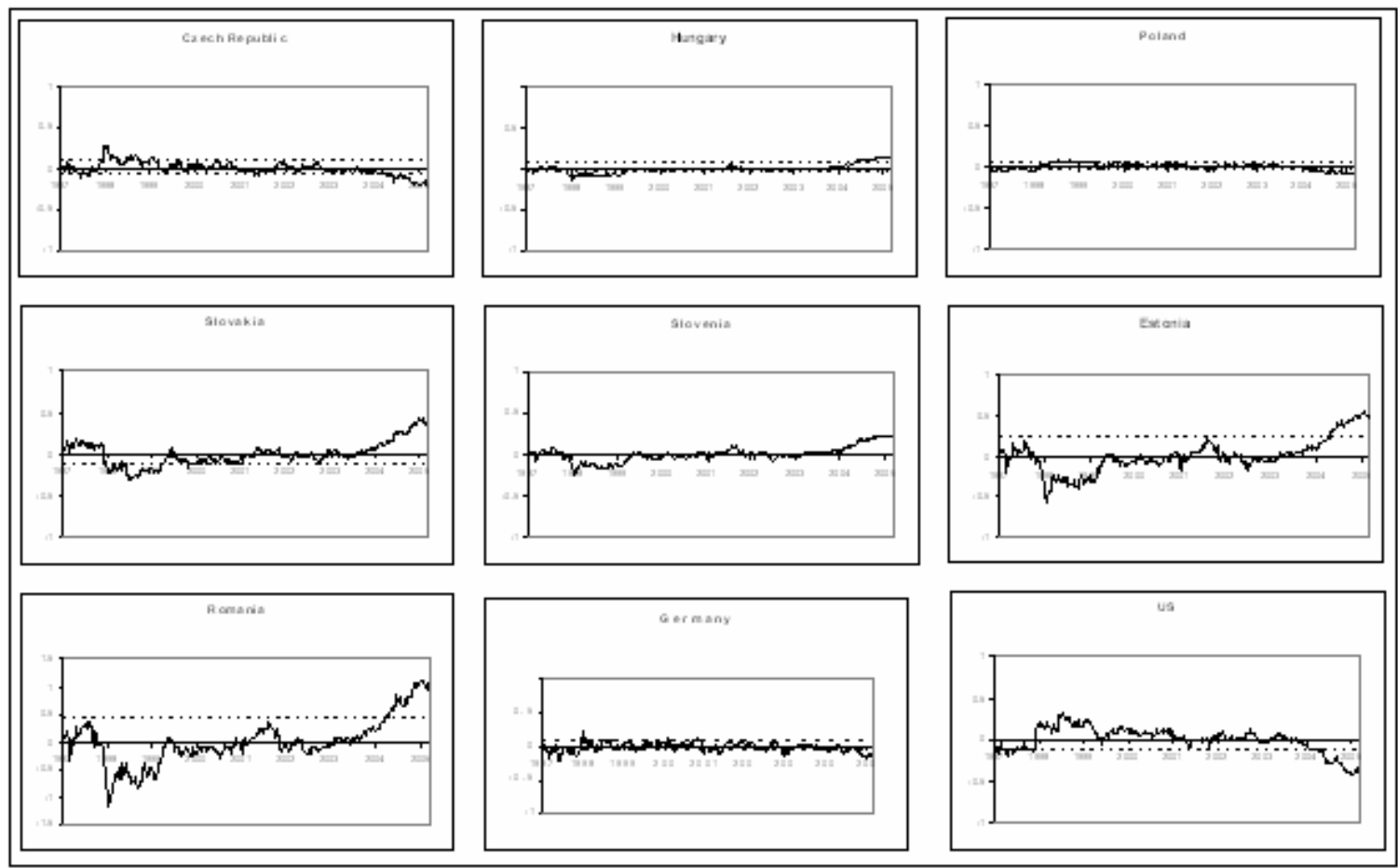


Figures 5: Conditional Correlation Coefficients

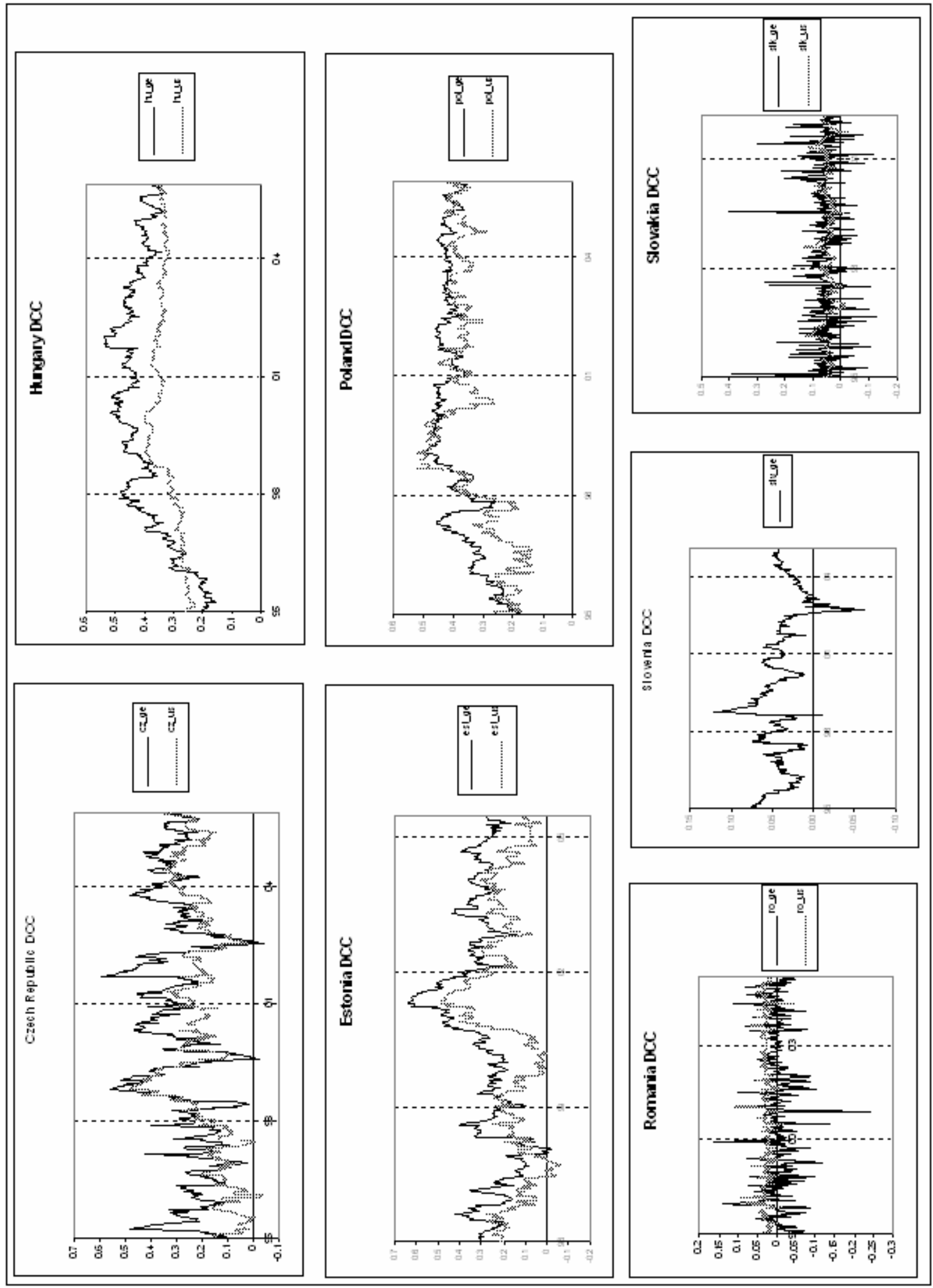


Figures 6: Time-Varying Regime Probabilities using MS-AR-ARCH-L model
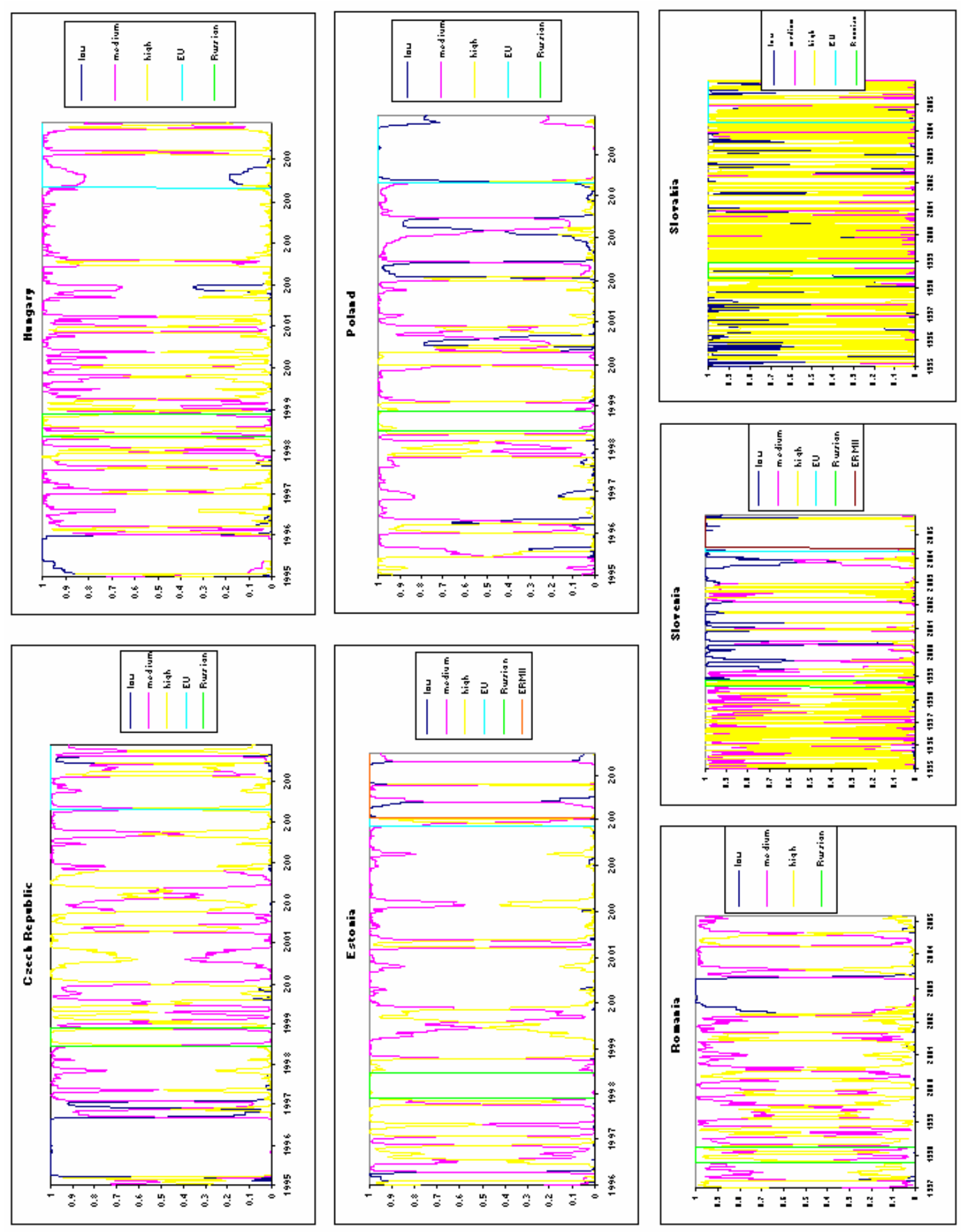